\title{
Use of Complementary and Alternative Medicine among Breast Cancer Women in Jordan
}

\author{
Kawther Hamash ${ }^{1 *}$ and Omar Khalil Hamdan ${ }^{2}$ \\ ${ }^{1}$ School of nursing, Indiana University-Fort Wayne, USA. \\ ${ }^{2}$ Section of Anatomical Pathology, University of Jordan Hospital, Jordan.
}

*Corresponding author: Kawther Hamash, Assistant professor, School of Nursing, Indiana University-Fort Wayne (IUFW), Liberal Arts Building, LA 309-D, 2101 E. Coliseum Blvd., Fort Wayne, IN 46805, USA.
Received Date: June 23, 2020

Published Date: July 15, 2020

\begin{abstract}
Purpose of the study: This study aimed to determine the use of Complementary and Alternative Medicine (CAM) and its associated demographic factors among breast cancer patients in Jordan.

Methods: A cross-sectional study was conducted. Patient demographic and clinical characteristics were collected using a self-administered survey that included practices and CAM therapies used in Jordan.

Findings: Two hundred and fifty-six participants between 18 and 65 years completed the questionnaire. Fifty percent of patients used more than one CAM therapy. The most commonly used CAM therapy was listening to the holy book, followed by herbal treatment, and nutritional therapy. The use of CAM was influenced by income, education, and marital status.

Conclusion: CAM use was found to be higher among well educated, married, and economically stable patients. The high prevalence of spiritual and nutritional CAM practices indicates that patients need psychological support to ease their unpleasant symptoms. Although cancer patients contemplate CAM therapies as important and favorable treatment, some CAM therapies can have a lethal effect on the patient's health outcomes. The high prevalence of using CAM therapies among breast cancer patients in Jordan oblige the need to boost awareness among health practitioners' and necessitates the need for patient's education regarding unsafe and lethal CAM practices. Future studies might investigate the physiological effect of CAM therapies on the patient's symptoms and health outcomes to report evidence of its effectiveness. More studies should investigate the potential side effects and possible interactions between CAM therapies and conventional treatment.
\end{abstract}

\section{Introduction}

Most breast cancer patients endure excruciating and debilitating symptoms throughout their disease and treatment phases. Most breast cancer symptoms are difficult to manage [1,2]. Cancer symptoms can result from the disease process, cancer treatment, or other external factors and are classified into physical, psychological, and cognitive symptoms [1-3]. Eighty percent of breast cancer patients who completed their treatment regimen reported having multiple symptoms. Pain, fatigue, feeling irritable, insomnia, feeling nervous, worrying, dry mouth, feeling sad, drowsiness, and distress were reported as the ten most commonly reported symptoms among cancer patients [4-8]. The experience of multiple symptoms can worsen the patient's distress level and lead to poor quality of life (QOL).

Excruciating pain and fatigue caused by breast cancer or its treatment are the most challenging aspects of symptom management. To reduce the distress level, patients may self-manage their cancer symptoms using complementary and alternative medicine (CAM) [9]. CAM describes products and practices that do not fall under standard medical care. The NCCAM describes CAM as diverse medical practices and products that do not belong to conventional medicine [9]. 
CAM has been widely used worldwide but limited literature exists on its use among breast cancer patients in Jordan [10-12]. In the middle east, CAM use has been documented among patients with chronic diseases including cancer patients in United Arab Emirates, Saudi Arabia, Egypt, Kuwait, Lebanon, and Jordan [13]. It is noteworthy that $70 \%$ of individuals with chronic diseases uses CAM therapies without consulting a physician while $90 \%$ of users considers CAM to have fewer side effects compared to conventional medicine [14]. The pattern of using CAM among cancer patients might vary based on spiritual beliefs, religious values, socioeconomic status, and geographical location [10-12,15]. For example, Mobed et al. (2009) found that the use of CAM was affected by differences in education level, marital status, and income level [15].

Today, many breast cancer patients use CAM for a variety of reasons, such as availability and accessibility of different CAM modalities such as dissatisfaction with conventional treatment, desperation, increased need for more control over personal health, and belief that CAM has the potential to enhance their wellbeing. Although breast cancer patients may perceive CAM as natural nonpharmacological treatment, some do not recognize that CAM might be harmful [16-18].

In the Middle East, CAM therapy is widely used for the treatment of affective, behavioral, cognitive, and sociocultural aspects of cancer [9]. In Jordan, $71.6 \%$ of patients with different chronic diseases reported using multiple CAM modalities45. Among cancer patients, $56.6 \%$ of cancer patients in Jordan used CAM therapy, of which $33 \%$ were female patients regardless of the cancer type11. In Middle Eastern culture, spirituality is considered a key factor in curing disease. Breast cancer patients start to become more attached to their religious practices to relieve some of their symptoms. Most breast cancer patients using CAM find the treatment appealing to their values and beliefs about life, fulfilling aspects that they could not find in conventional medicine. Use of CAM enables them to take control of their lives and saves them from the negative impacts of conventional medicine, such as fatigue and pain [20].

Most of the CAM modalities used in the Middle East are mentioned in the Quran (the Islamic holy book), such as honey, camel milk, drinking zamzam water (water from Mecca), and cupping (Hijama) [34]. Likewise, Muslim and non-Muslim breast cancer patients alike tend to use CAM measures that have no religious nature, such as exercise, hypnosis, acupuncture, biofeedback, herbal remedies, and guided meditation. Psychosocial and physical CAM can offer relief of symptoms among breast cancer patients [21].

Although some CAM modalities are therapeutic, their use might not be safe, and wellbeing is not guaranteed to improve. Additionally, the use of CAM may not be compatible with the patient's conventional treatment. For instance, although massage appears promising for managing symptoms and improving QOL, the available scientific evidence does not show that it slows or reverses the growth of cancer. Thus, evidence of the effectiveness of CAM in cancer patients is sparse [23,24]. Therefore, clinicians need to be attentive about patients' use of CAM treatment to be aware of unexpected or adverse interactions. The aim of the present study was to determine the prevalence of using CAM and its associated sociodemographic factors (i.e., household income, education level, marital status, age, disease stage, and type of health insurance) among breast cancer patients in Jordan that might have been associated with higher CAM prevalence.

\section{Method}

This study used a cross-sectional design. The study was conducted in a university teaching hospital between December 2017 and February 2018 and received ethical approval from appropriate IRB authorities. The present study was a part of a parent study. In the parent study, participants were recruited if they were female, diagnosed with breast cancer, and not diagnosed with other chronic diseases. Participants signed an informed consent prior to starting data collection. Patient demographic and clinical characteristics were collected using self-administered survey. The study took place in the outpatient setting. The survey included patient's age, marital status, education level, monthly income, and cancer stage. The research team developed a list of CAM therapies and practices that are used by breast cancer patients in Jordan, including religious practices such as reading religious book, herbal treatments, consuming nutritional supplements, listening to music, and practicing yoga and reiki. This list was then added to the data collection tool. Participants could add CAM practices that were not included on the list.

Data were analyzed using descriptive statistics with SPSS (version 24) to describe the sample characteristics and the prevalence of CAM practices. A chi-square test was used to determine any associations between age, education, income, marital status, or disease stage with the use of CAM.

The chi-square test was conducted to determine any statistically significant association between the "use" or "not use" of CAM and the demographic variables of the participants. The study hypothesis for the test was that there is a statistically significant association between the demographic variables and the "use" or "not use" of CAM therapies.

\section{Results}

\section{Sample characteristics}

In the parent study, two hundred and fifty-six participants completed the questionnaire. Participant age ranged between 18 and 65 years. Three quarters of the sample were aged 45 or older. Over half had completed an undergraduate degree, while the remainder had completed high school or less. Most of the study sample were in stage three of breast cancer. All participants 
were outpatients at the time of the study. Sociodemographic characteristics are provided in Table 1.

Fifty percent of patients used more than one CAM therapy. The most commonly used therapy was listening to or reading the holy book (Quran) (21.2\%), followed by herbal treatment (10.8\%), and nutritional therapy (3.8\%). Only $11.5 \%$ of the participants did not use any form of CAM.

\section{Relationship between CAM use and sociodemographic characteristics}

The use of CAM was influenced by income, education, and marital status. As the income of the participants increased, participants were significantly more likely to use CAM therapies $(\chi 2=28.154, \mathrm{p}<0.01)$. The findings also indicated that the use of CAM was influenced by the level of education of the participants. As

Table 1: Patient's sociodemographic characteristics.

\begin{tabular}{|c|c|}
\hline & N (\%) Health insurance \\
\hline Public health insurance & 237 (91.5) \\
\hline Private health insurance & $6(2.3)$ \\
\hline Uninsured & $16(6.1)$ \\
\hline \multicolumn{2}{|c|}{ Age (years) } \\
\hline $18-34$ & $33(12.7)$ \\
\hline $35-44$ & $88(33.9)$ \\
\hline$>=55$ & $138(53.2)$ \\
\hline \multicolumn{2}{|c|}{ Monthly Household income (JD) } \\
\hline$<=100$ & $14(5.4)$ \\
\hline $100-250$ & $34(13.1)$ \\
\hline $250-450$ & $100(38.6)$ \\
\hline $450-650$ & $85 \quad 32.8)$ \\
\hline$>=650$ & $26(10.0)$ \\
\hline \multicolumn{2}{|c|}{ Education level } \\
\hline Less than secondary school & $39(15.0)$ \\
\hline High school school & $37(14.2)$ \\
\hline Community college & $29(11.1)$ \\
\hline Bachelor & $141(54.4)$ \\
\hline Master & $8(3.0)$ \\
\hline Doctoral & $5(1.9)$ \\
\hline \multicolumn{2}{|c|}{ Marital status } \\
\hline Single & $34(13.1)$ \\
\hline Married & $174(67.1)$ \\
\hline Separated & $1(0.3)$ \\
\hline Widowed & $44(16.9)$ \\
\hline Divorced & $6(2.3)$ \\
\hline \multicolumn{2}{|c|}{ Disease stage } \\
\hline 1st stage & $69(26.6)$ \\
\hline 2nd stage & $63(24.3)$ \\
\hline 3rd stage & $79(30.5)$ \\
\hline 4 th stage & $48(18.5)$ \\
\hline
\end{tabular}

the level of education increased, participants were more likely to use CAM therapies $(\chi 2=26.627, p<0.01)$. CAM was also associated significantly with marital status $(\chi 2=19.790, p<0.01)$. Married participants were more likely to use CAM (70.4\%) compared to single (13\%), widowed (14.3\%), and divorced women (2.2\%). This indicated that married couples are more likely to use CAM therapies compared to their counterparts (Table 2).

The chi-square results show that the use of CAM was not correlated with health insurance, age, or stage of disease (see Table 2). The results showed that CAM use found common among elderly individuals and individuals with government health insurance. However, the findings were not statistically significant between the use of CAM therapies and type of health insurance $(\chi 2=3.623$, p $>0.05)$, age $(\chi 2=9.902, p>0.05)$, or stage of disease $(\chi 2=0.274, p$ $>0.05$ ) (Table 2). 
Table 2: Results of Chi-square Test and Descriptive Statistics use of complementary and alternative therapies.

\begin{tabular}{|c|c|c|c|}
\hline \multicolumn{3}{|c|}{ Complementary and alternative therapies } & \multirow{2}{*}{$\chi^{2}$} \\
\hline & Yes $N(\%)$ & No N (\%) & \\
\hline \multicolumn{3}{|c|}{ Health Insurance } & \multirow[b]{2}{*}{3.62} \\
\hline Governmental health insurance & $213(92.6)$ & $24(82.8)$ & \\
\hline Private health insurance & $5(2.2)$ & $1(3.4)$ & \multirow[b]{4}{*}{9.9} \\
\hline Uninsured & $12(5.2)$ & $4(13.8)$ & \\
\hline \multicolumn{3}{|c|}{ Age (years) } & \\
\hline 18-34 years & $32(13.9)$ & $1(2.4)$ & \\
\hline $35-54$ years & $81(35.2)$ & $7(25.1)$ & \multirow[b]{4}{*}{$28.15^{* *}$} \\
\hline$>=55$ & $117(50.9)$ & $21(72.4)$ & \\
\hline \multicolumn{3}{|c|}{ Monthly Household Income (JD) } & \\
\hline$<250$ & $34(14.8)$ & $14(48.3)$ & \\
\hline $250-650$ & $171(74.4)$ & $14(48.3)$ & \multirow[b]{4}{*}{$26.63^{* *}$} \\
\hline$>=650$ & $25(10.9)$ & $1(3.4)$ & \\
\hline \multicolumn{3}{|c|}{ Education Level } & \\
\hline less than secondary School & $28(12.2)$ & $11(37.9)$ & \\
\hline High school & $29(12.6)$ & $8(27.6)$ & \\
\hline Community college & $25(10.9)$ & $4(13.8)$ & \\
\hline Bachelor & 136 (59.1) & $5(17.2)$ & \\
\hline Master degree & $7(3.1)$ & $1(3.4)$ & \\
\hline Doctoral degree & $5(2.2)$ & $0(0.0)$ & \\
\hline \multicolumn{3}{|c|}{ Marital Status } & \multirow[b]{2}{*}{$19.79^{* *}$} \\
\hline Single & $30(13.0)$ & $4(13.8)$ & \\
\hline Married & $162(70.4)$ & $12(41.4)$ & \multirow[b]{6}{*}{0.27} \\
\hline Separated & $0(0.0)$ & $1(3.4)$ & \\
\hline Widow & $33(14.3)$ & $11(37.9)$ & \\
\hline Divorced & $5(2.2)$ & $1(3.4)$ & \\
\hline \multicolumn{3}{|c|}{ Disease Stage } & \\
\hline First stage & $61(26.5)$ & $8(27.6)$ & \\
\hline Second stage & 55 (23.9) & $8(27.6)$ & \\
\hline Third stage & $71(30.9)$ & $8(27.6)$ & \\
\hline Fourth stage & 43 (18.7) & $5(17.2)$ & \\
\hline
\end{tabular}

\section{Discussion}

This study evaluated the use of CAM among breast cancer patients in Jordan. The prevalence of CAM use was high. Major findings indicated a significant correlation between income, level of education, and marital status with CAM therapy use. Breast cancer patients who are economically stable, married, and well educated appear to use CAM therapy more than others do.

The prevalence of CAM use among breast cancer patients after being diagnosed ranges from $40-75 \%$ worldwide [24-26]. In this study, the prevalence of CAM use among breast cancer patients was $88 \%$. This is in line with previous research of the National Health Interview Survey (NHIS) in 2012 and 2007 [27] and explains the high prevalence of CAM among women with breast cancer in this study $[1,26-28,30,31]$.
Geographical location, socioeconomic status, religious beliefs, and sociocultural perception and beliefs might play an imperative role in the high incidence of using CAM $[10,12,32,33]$. For instance, recently there has been an increase in the consumption of camel products, zamzam water, and honey in Saudi Arabia, due to cultural practices and common resources available30. Moreover, in the Middle East, nutritional and herbal CAM remedies are widely available and sold to the public on a daily basis. Thus, the easy and open access to a variety of conventional medicine options in the Middle East also factors into why the prevalence of CAM in Jordan is high.

This study found that most breast cancer patients used more than two forms of CAM treatments. Spiritual treatments were used most often, indicating the importance of spiritual and emotional 
wellbeing during the different stages of the disease. Although the prevalence of using spiritual and religious practices varies among cancer research [32], these practices can help patients deal with their emotional distress [34].

Spiritual practices were followed in popularity by herbal treatments [24,35,36-40] and nutritional supplements [26,27], which was in congruence with other studies. Although herbal and nutritional supplements may sound natural and healthy, some might be toxic or interact with other medical therapies [17]. For instance, some dietary CAM therapies, such as shark cartilage, are known to cause hepatotoxicity that can lead to mortality [16].

Although the relationship between type of health insurance and the prevalence of using CAM was not significant, study findings showed that the highest percentage of CAM use was among patients who relied on government (public) insurance (92.2\%) and those who were uninsured (5.2\%). This is in line with other studies that showed that CAM use was related to economic gradient [45]. Because some conventional therapies are not covered by health insurance and the cost of conventional therapy is high patients look for cheaper options to manage their disease and symptoms [42]. Patients who had higher income and were privately insured likely received better management of their disease and symptoms, leading to a lower need to manage uncontrolled symptoms. Conversely, uninsured and publicly insured patients were looking for new and perhaps cheaper treatments to better manage their symptoms. The low percentage of CAM users among uninsured patients might be due to the extra cost of using CAM therapies in addition to paying the cost of their medical treatment.

Relationships were similarly shown to have a positive association with the choice to use CAM, in congruence with results from prior studies [11,32]. Married individuals are emotionally linked to their partners, who offer them support and give them a reason to strive for longer survival. They are generally more optimistic about recovery and are therefore more open to trying other forms of treatment. This is in agreement with prior literature that showed that single cancer patients lack intimate support and tend to be pessimistic about their recovery [47].

As in previous research, education was significantly associated with CAM use $[11,44,45]$. This may be largely due to lack of education leading to rigidity in thinking. Uneducated patients may not be aware of safe and efficient alternative therapies as an option that can reduce treatment side effects or improve psychological wellbeing. However, patients who had higher educational degrees tended to use CAM less or not at all. This might be due to their advanced level of knowledge; highly educated patients might consult their health care providers to know more about safe and effective CAM options, rather than trying random forms of CAM treatment [22,25]. While education can encourage open-mindedness of patients to try new CAM therapies and increase their awareness of available alternative health practices, another study showed level of education had no role in this decision [29]. The difference in findings might be related to differences in the study sample, geographical location, and spiritual beliefs.

Several studies have reported an association between aging and CAM use $[1,24,36]$. In this study, the highest percentage of CAM use was among patients above 45 years, with the most being in patients aged over 65 . This may be due to older patients having lower tolerance for severe symptoms and treatment side effects, leading them to look for new approaches to lower their distress level and minimize the side effects of conventional therapy [44]. However, in line with some other studies [25, 28, 43], our results did not support an association between age and CAM use. This is may be because young patients tend to be more worried about their diagnosis, life, and family than older patients who have lived a long life [47].

\section{Limitations}

Our study had some limitations. The data reported general categories of CAM therapy, which limited our ability to investigate the prevalence of possible toxic or contraindicated CAM supplements used among the sample. Study results might also have been affected by social desirability bias: patients might have chosen some CAM therapy items or abstained from reporting others due to the presence of research team members at the time of data collection.

\section{Conclusion}

Many breast cancer patients use a variety of CAM therapies. Herbal, dietary, nutritional supplements, and spiritual or religious practices were the most highly used CAM practices among breast cancer patients in Jordan. Income, education, and marital status were demographic factors associated with higher CAM use. Patients who were married and were more educated tended to use more CAM therapy, perhaps trying to extend their survival. The culture of Middle East nationalities embraces holistic practices as part of healing and recovery. While some CAM therapies are considered beneficial, others are known to be the opposite. Patients may fail to realize that these therapies could be a source of chemicals that can interact with conventional medicine to harmful effect. Monitoring patient consumption of such therapies is necessary to avoid side effects. It is also necessary to educate health care providers about CAM so they can better manage their patients safely and avoid possible side effects.

\section{Clinical Significance}

This study aids in increasing the awareness of health practitioners about the background factors behind the high prevalence of CAM therapy. Although cancer patients contemplate CAM therapies as important and favorable treatment, some CAM therapies can have a lethal effect on the patient's health outcomes. The high prevalence of using CAM therapies among breast cancer patients in Jordan oblige the need to boost awareness among 
health practitioners' and necessitates the need for patient's education regarding unsafe and fatal CAM practices. Future studies might investigate the physiological effect of the publicly used CAM therapies in the Middle East on the patient's symptoms and health outcomes to report evidence of its effectiveness. More studies should investigate the potential side effects and possible interactions between CAM therapies and conventional treatment.

\section{Informed Consent}

Informed consent was obtained from all individual participants included in the study.

\section{Research involving Human participants and Animals}

All procedures performed in this study were in accordance with the ethical standards of the institutional and /or national research committee (The University of Jordan Institutional review board, Reference number: 2018/479) and with the 1964 Helsinki declaration and its later amendments or comparable ethical standards.

\section{Funding Sources}

This research received no specific grant from any funding agency in the public, commercial, or not-for-profit sources.

\section{Conflict of Interest}

Author declare no conflict of interest.

\section{References}

1. Chang KH, Brodie R, Choong MA, Sweeney KJ, Kerin MJ (2011) Complementary and alternative medicine use in oncology: A questionnaire survey of patients and health care professionals. BMC Cancer 11: 196

2. Portenoy RK, Thaler HT, Kornblith AB, Lepore JM, Friedlander-Klar H, et al. (1994) Symptom prevalence, characteristics and distress in a cancer population. Qual Life Res 3(3): 183-189.

3. Deshields TL, Potter P, Olsen S, Liu J, Dye L (2011) Documenting the Symptom Experience of Cancer Patients. J Support Oncol 9(6): 216-223.

4. Kim H-J, Barsevick AM, Tulman L (2009) Predictors of the Intensity of Symptoms in a Cluster in Patients with Breast Cancer. J Nurs Sch 41(2):158-165.

5. Beck SL, Dudley WN, Barsevick A (2005) Pain, Sleep Disturbance, and Fatigue in Patients with Cancer: Using a Mediation Model to Test a Symptom Cluster. Oncol Nurs Forum 32(3): 542

6. Laird BJ, Scott AC, Colvin LA, Mckeon A-L, Murray GD, et al. (2011) Pain Depression, and Fatigue as a Symptom Cluster in Advanced Cancer. J Pain Symptom Manage 42(1): 1-11.

7. Miaskowski C, Aouizerat BE (2007) Is There a Biological Basis for the Clustering of Symptoms? Sem Oncol Nurs 23(2): 99-105.

8. Pettersson G, Berterö C, Unosson M, Börjeson S (2013) Symptom prevalence, frequency, severity, and distress during chemotherapy for patients with colorectal cancer. Support Care Cancer 22(5): 1171-1179.

9. (2019) National Center for Complementary and Integrative Health. Alternative or Integrative: What's in a name?

10. Harris PE, Cooper KL, Relton C, Thomas KJ (2012) Prevalence of complementary and alternative medicine (CAM) use by the general population: a systematic review and update. Int J Clin Pract 66(10): 924939.
11. Al-Momani IN, AL-Tawalbeh DM (2015) Usage of complementary and alternative medicine among cancer patients in Jordan. Glob science res J 3(6): 152-159.

12. Posadzki P, Alotaibi A, ErnstE (2012) Prevalence of use of complementary and alternative medicine (CAM) by physicians in the UK: a systematic review of surveys. Clin Med (Lond) 12(6): 505-512.

13. Balkees AB, Hasan AA (2010) Self-reported use of complementary and alternative medicine (CAM) products in topical treatment of diabetic foot disorders by diabetic patients in Jeddah, Western Saudi Arabia. BMC Res Notes 3:254.

14. Mathew E, Muttappallymyalil J, Sreedharan J, John LJ, John J, et al. (2013) Self-reported use of complementary and alternative medicine among the health care consumers at a tertiary care center in Ajman, United Arab Emirates. Ann Med Health Sci Res 3(2):215-219.

15. Mobed K, Liu R, Stewart S, Wrensch M, McCoy L, et al. (2009) Quality of Life and Patterns of Use of Complementary and Alternative Medicines Among Glioma Patients. J Support Oncol 7(6): W23-W31.

16. Ashar B, E vargo (1996) Shark Cartilage-Induced Hepatitis. Ann Intern Med 125(9): 780-781.

17. Navarro V, Barnhart H, Bonkovsky HL, Davern T, Fontana RJ, et al. (2014) Liver injury from herbals and dietary supplements in the U.S. Druginduced liver injury network. Hepatology 60(4): 1399-1408.

18. Teo DCH, Ng PSL, Tan SH, Lim AT, Toh DSL, et al. (2016) Drug-induced liver injury associated with Complementary and Alternative Medicine: a review of adverse event reports in an Asian community from 2009 to 2014. BMC J Complement Altern Med 16: 192.

19. Woolf CJ (2011) Central sensitization: Implications for the diagnosis and treatment of pain. Pain 152(3 Suppl): S2-S15.

20. Subramani R, Lakshmanaswamy R (2017) Complementary and Alternative Medicine and Breast Cancer. Prog Mol Biol Transl Sci 151: 231-274.

21. MacDonald RN, Hugi MR, Graydon JE, Beaulieu MD, Caines J, et al. (1998) The management of chronic pain in patients with breast cancer. Can Med Assoc J 158: 71-81.

22. Liu WC, Zheng ZX, Tan KH, Meredith GJ (2017) Multidimensional Treatment of Cancer Pain. Curr Oncol Rep 19(2): 10.

23. Satija A, Ahmed SM, Gupta R, Ahmed A, Rana SP, et al. (2014) Breast cancer pain management - a review of current \& novel therapies. Indian J Med Res 139(2): 216-225.

24. Bahall M (2017) Prevalence, patterns, and perceived value of complementary and alternative medicine among cancer patients: a cross-sectional, descriptive study. BMC Compl Altern Med 17(1): 345.

25. Greenlee H, Kwan ML, Ergas IJ, Sherman KJ, Krathwohl SE, et al. (2009) Complementary and alternative therapy use before and after breast cancer diagnosis: The Pathways Study. Breast Cancer Res Treat 117(3): 653-665.

26. Farooqui M, Hassali MA, Shatar AKA, Farooqui MA, Saleem F, et al. (2016) Use of complementary and alternative medicines among Malaysian cancer patients: A descriptive study. J Tradit Complement Med 6(4): 321-326.

27. Kessel KA, Lettner S, Kessel C, Bier H, Biedermann T, et al. (2016) Use of Complementary and Alternative Medicine (CAM) as Part of the Oncological Treatment: Survey about Patients' Attitude towards CAM in a University-Based Oncology Center in Germany. Plos One 11(11): e0165801.

28. Paul M, Davey B, Senf B, Stoll C, MuÈnstedt K, et al. (2013) Patients with advanced cancer and their usage of complementary and alternative medicine. J Cancer Res Clin Oncol 139(9): 1515-1522.

29. Barnes PM, Powell-Griner E, Mcfann K, Nahin RL (2004) Complementary and alternative medicine use among adults: United States, 2002. Adv Data 27(343): 1-19. 
30. Mollaoglu M, Aciyurt A (2013) Use of complementary and alternative medicine among patients with chronic diseases. Acta Clin Croat 52(2): 181-188.

31. Algier LA, Hanoglu Z, Özden G, Kara F (2005) The use of complementary and alternative (non-conventional) medicine in cancer patients in Turkey. Eur J Oncol Nurs 9(2): 138-146.

32. Abuelgasim KA, Yousef, Alenzi T, Alhazzani A, Jazieh AR (2018) The use of complementary and alternative medicine by patients with cancer: a cross-sectional survey in Saudi Arabia. BMC Complement Altern Med 18(1): 88.

33. Naja F, Anouti B, Shatila H, Akel R, Haibe Y, et al. (2017) Prevalence and Correlates of Complementary and Alternative Medicine Use among Patients with Lung Cancer: A Cross-Sectional Study in Beirut, Lebanon. Evid Based Complement Alternat Med 2017: 8434697.

34. Moschèn R, Kemmler G, Schweigkofler H, Holzner B, Dünser M, et al. (2001) se of alternative / complementary therapy in breast cancer patients - a psychological perspective. Support Care Cancer 9(4): 267274.

35. Molassiotis A, Fernadez-Ortega P, Pud D, Ozden G, Scott JA, et al. (2005) Use of complementary and alternative medicine in cancer patients: $a$ European survey. Ann Oncol 16(4): 655-663.

36. Abdallah R, Xiong Y, Lancaster JM, Judson PL (2015) Complementary and Alternative Medicine Use in Women with Gynecologic Malignancy Presenting for Care at a Comprehensive Cancer Center. Int J Gyne Cancer 25(9): 1724-1730

37. Molassiotis A, Fernandez-Ortega P, Pud D, Ozden G, Platin N, (2005) et al. Complementary and alternative medicine use in colorectal cancer patients in seven European countries. Comp Therap Med 13(4): 251257.

38. Molassiotis A, Browall M, Milovics L, Panteli V, Patiraki E, et al. (2006) Complementary and alternative medicine use in patients with gynecological cancers in Europe. Int J Gynecol Cancer 16(S1): 219-224.

39. Molassiotis A, Scott JA, Kearney N, Pud D, Magri M, et al. (2006) Complementary and alternative medicine use in breast cancer patients in Europe. Support Care Cancer 14 (3): 260-267.
40. Nazik E, Nazik H, Api M, Kale A, Aksu M (2012) Complementary and Alternative Medicine Use by Gynecologic Oncology Patients in Turkey. Asian Pac J Cancer Prev 13(1): 21-25.

41. Lee MM, Chang JS, Jacobs B, Wrensch MR (2002) Complementary and Alternative Medicine Use Among Men with Prostate Cancer in 4 Ethnic Populations. Am J Public Health 92(10): 1606-1609.

42. Alameddine M, Naja F, Abdel-Salam S, Maalouf S, Matta C (2011) Stakeholders perspectives on the regulation and integration of complementary and alternative medicine products in Lebanon: a qualitative study. BMC Complement Altern Med 11:71

43. Luger T, Cotter KA, Sherman AM (2009) It's all in how you view it: Pessimism, social relations, and life satisfaction in older adults with osteoarthritis. Aging Ment Health 13(5): 635-647.

44. Burke A, Richard L, Nahin RL, Stussman BJ (2015) Limited Health Knowledge as a Reason for Non-Use of Four Common Complementary Health Practices. PLoS One 10(6): e0129336.

45. Sárváry A, Sárváry A (2019) Use of complementary and alternative medicine among breast cancer patients in Hungary: A descriptive study. Comp Therap Clin Pract 35: 195-200.

46. Er O, Mistik S, Ozkan M, Ozturk A, Altinbas M (2008) Factors Related to Complementary/Alternative Medicine use among Cancer Patients in Central Anatolia. Tumori 94(6): 833-837.

47. Chui PL, Abdullah KL, Wong LP, Taib NA (2014) Prayer-for-health and complementary alternative medicine use among Malaysian breast cancer patients during chemotherapy. BMC Complement Altern Med 14: 425 .

48. Wazaify M, Alawwa I, Yasein N, Al-Saleh A, Afifi FU (2013) Complementary and alternative medicine (CAM) use among Jordanian patients with chronic diseases. Complement Ther Clin Pract 19(3): 153-157. 